\title{
Potential Use of Rice Husk Ash (RHA) in Flowable Fill Concrete
}

\author{
Kazi Islam ${ }^{1}$ and Zahid Hossain,"* \\ ${ }^{1}$ College of Engineering, 504 University Loop, Arkansas Bioscience Institute (ABI), ABI-233W, State University, Jonesboro, AR 72467 \\ ${ }^{2}$ College of Engineering, Arkansas State University, PO Box 1740, LSW\#246, State University, Jonesboro, AR 72467
}

\begin{abstract}
Flowable fill is a self-compacting material, which has been developed in recent years. It is a relatively new construction technology where rapid construction is needed for different applications such as backfilling walls, sewer trenches, bridge abutments, conduit trenches, pile excavations, and retaining walls. The objective of this study is to evaluate the usage of RHA in producing low strength and self-consolidating flowable fill concrete (FFC). Two different RHA samples $(600 \mu \mathrm{m}$ and $150 \mu \mathrm{m})$ in three different percentages $(40 \%, 60 \%$, and $80 \%$ by the weight) of Ordinary Portland Cement (OPC) have been used to prepare flowable fill mixture. The evaluation processes of these fresh FFC mixtures includes determination of strength, setting time, flowability, unit weight, and air content in the laboratory. Further, two field demonstration projects have been planned to evaluate their workability, placement, and in-service performance. Findings of this study will help the transportation and the construction agencies in finding a cost-effective construction material.
\end{abstract}

\section{Introduction}

Rice husk ash (RHA) is an agricultural residue produced by the rice industry. Rice husk $(\mathrm{RH})$ is the outer layer of the rice grain. RHA is produced from the burning process of rice husk (RH). About $20 \%$ of RH (by weight) remains as RHA after the incineration process. According to the US Department of Agriculture's national agricultural statistics [1], over 18 billion pounds (9 million tons) of rice were produced in 2016, which eventually generated 720 million of pounds ( 0.36 million tons) of RHA in the milling process. At present, there is no well-established beneficial application of RHA. Disposal of RHA in landfills cause air and water pollution in the surrounding areas. The proper use of RHA as a supplementary cementitious material (SCM) by concrete industries can bring low-cost construction. A higher percentage of silica $\left(\mathrm{SiO}_{2}\right)$ presents in RHA, which determines a highly reactive pozzolanic property [2]. In the controlled burning chamber, RHA contains amorphous or non-crystalline silica. Microporous cellular structure in RHA helps to conduct the pozzolanic reaction in presence of Ordinary Portland cement (OPC) [3]. Moreover, the hydration process in the concrete is also influenced by different particle sizes of RHA [4]. The $\mathrm{SiO}_{2}$ from the controlled combustion process of RHA helps to create a secondary CalciumSilicate-Hydrate (C-S-H) gel, which signifies the strength development of concrete.

Recently, the research team has conducted a study to incorporate RHA in regular concrete [5]. It was found that the coarse RHA particles (Particle Size: $600 \mu \mathrm{m} \&$ $150 \mu \mathrm{m})$ modified concrete exhibited significantly lowstrength compared to the regular concrete (the Control). On the other hand, incorporation of fine RHA particle
(Particle Size: $44 \mu \mathrm{m}$ ) in concrete improved the workability and the strength properties of concrete compared to the Control sample. Different durability tests such as alkali-silica reactivity (ASR) also suggested that coarse RHA produced by the local industry (Rice Foods) were not suitable for achieving durable concrete. However, it was recommended that the coarse RHA particles could have potential use in producing controlled low strength materials (CLSMs).

Over the past years, CLSMs including FFC mixtures have become new technologies in the construction industry. These mixtures can be used as backfill materials without any need for vibrations or compaction efforts. The FFC mixture is typically comprised of water, cement, fine aggregates, and often fly ash and some chemical admixtures. According to the ACI Committee 229 , the FFC is defined as a "self-compacting cementitious material that is in a flowable state at the time of placement and that has a specified compressive strength of $200 \mathrm{lb} / \mathrm{in}^{2}$ [pounds per square inch] or less at 28 days." The FFC is usually used as an alternative to compacted soil or granular backfill in different projects such as, in sewer and utility trenches, bridge abutments, pile excavation, and road cuts [6]. Different industrial by-product and waste product have been studied to produce FFC as well. Likewise, the use of RHA in producing low strength self-compacted concrete reduce the construction cost in a significant amount [7]. Similarly, use of scrap tire rubber as lightweight aggregate in FFC reduces its bleeding problem [8]. However, the applicability of local RHA in producing FFC has not been studied by any research group other than the current study. Field performance of RHAmodified FFC is also equally important before RHA can be recommended in producing FFC. The current study 
aims at reducing the research gap toward a sustainable of RHA by the concrete industry.

\section{Objectives}

The objective of this study to evaluate the performance of the flowable fill containing different types of RHA in various percentages. The evaluation will include, the determination of strength properties of RHA modified flowable fill, set time tests and flow properties of the modified flowable mixture.

\section{Materials and methodologies}

In this study, the properties of modified and unmodified FFC will be compared to evaluate the effect of RHAs as pozzolanic materials. According to the physical and mechanical properties of standard FFC, the mix designs of different flowable fill will be studied to adopt a feasible one for the local conditions and appropriate for RHA. Specific criteria including flowability, volume stability, and the setting time will be verified with respect to the ArDOT guidelines. Mix designs from different construction agencies have been considered in this study. Cylindrical samples will be made from the unmodified and modified flowable fill mixes, and they will be tested to evaluate different mechanical properties such as compressive strength and durability.

\subsection{Materials}

Cement, RHA and fine aggregate (FA) are blended to produce FFC. The FA (stone sand) has been collected from a local ready-mix concrete plant located in Paragould, AR. Type-I OPC containing specific gravity of 3.15 has also been collected from the same plant. According to the ASTM C136 method, FA was sieved and the fineness modulus (FM) was found to be 2.60. As per ASTM C128-15, the specific gravity of the fine aggregate was found to be 2.58 and the absorption value for the fine aggregate was determined as $0.3 \%$.

Figure 1 shows the pictorial views of two different types of RHA (RHA-1: $600 \mu \mathrm{m}$, and RHA-2: 150) which have considered in this study. RHA-1 and RHA-2 samples were collected from Riceland Foods Inc. From Figure 1, it is also seen that both RHA-1 and RHA-2 are dark black in color. Three different percentages $(40 \%$, $60 \%$, and $80 \%$ by the weight of OPC) are being used to prepare FFC mixture samples. The dark color of RHA-1 and RHA-2 indicates the high percentage of unburnt carbon [9], whereas the grey color indicates a low percentage of unburnt carbon.

Table 1 shows the physical and chemical data of RHAs used in this study. These data were collected from the corresponding suppliers, and they were compared with AASHTO M 321-04 (Standard Specification for High-Reactivity Pozzolans for Use in Hydraulic-Cement Concrete, Mortar, and Grout). From Table 1, it is also seen that the reactive oxide specifications, per AASHTO M 321-04, were satisfied for all RHA samples. It also appears that neither RHA-1 nor RHA-2 satisfied the moisture content and the loss on ignition specifications.

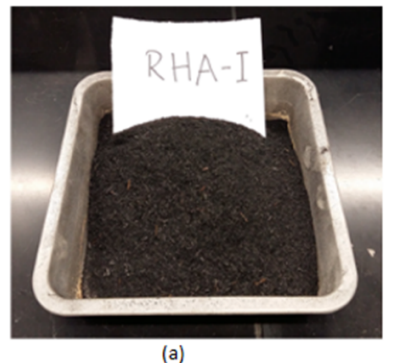

(a)

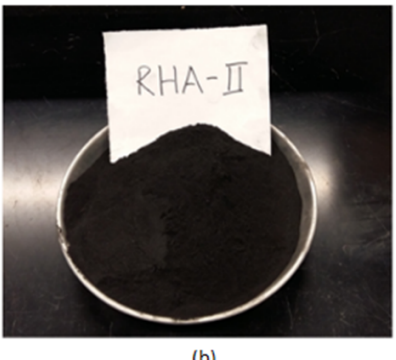

(b)
Fig. 1. (a) 600-RHA, and (b) 150-RHA.

Table 1. Chemical properties of RHA.

\begin{tabular}{|c|c|c|c|}
\hline Chemical Properties & RHA-1 & RHA-2 & $\begin{array}{c}\text { AASHTO } \\
\text { M 321-04 }\end{array}$ \\
\hline $\begin{array}{c}\text { Reactive oxides } \\
\left(\mathrm{SiO}_{2}+\mathrm{Al}_{2} \mathrm{O}_{3}+\mathrm{Fe}_{2} \mathrm{O}_{3}\right)\end{array}$ & $95.50 \%$ & $95.50 \%$ & $\begin{array}{c}75 \% \\
(\text { minimum })\end{array}$ \\
\hline $\begin{array}{c}\text { Loss on ignition } \\
(\mathrm{LOI})\end{array}$ & $8.98 \%$ & $8.98 \%$ & $\begin{array}{c}6 \% \\
\text { (maximum) }\end{array}$ \\
\hline Moisture content & $3-5 \%$ & $3-5 \%$ & $\begin{array}{c}3 \% \\
\text { (maximum) }\end{array}$ \\
\hline
\end{tabular}

\subsection{Experimental details}

The specific surface area of the cementitious material plays a vital role in the development of concrete strength, and it is directly correlated with the particle size and fineness of the materials [10-12]. Specific surface areas of SCMs and Type I OPC were determined by following the BET (Brunauer, Emmett, and Teller) method. A NOVA 2200e analyzer was used to measure the specific surface area. As per the ASTM D1993-03 method, the multi-point BET mode of the NOVA 2200e analyzer was followed in the test procedure.

Properties of fresh flowable fill concrete and hardened concrete were determined in accordance with the ASTM guidelines. The slump and flow consistency, setting time, temperature, air content, and unit weight of the fresh flowable fill mix will be determined in accordance with ASTM C143, ASTM C403, ASTM C1064, ASTM C231, and ASTM C138, respectively.

Concrete cylinders $(150-\mathrm{mm}$ diameter and $300-\mathrm{mm}$ height) will be cast in the laboratory. After 24 hours of casting, the cylinders will be demolded and cured in a water bath, as per the ASTM C31 method. A curing period of 28 days will be maintained, while a room temperature of $25^{\circ} \mathrm{C}$ will need to be maintained during the curing period. Compressive strengths at 7, 14, 21 and 28 days will be measured as per the ASTM C39-04a method. Test results of at least two specimens of each test condition will be collected. Splitting tensile strength of the 28-day cured cylindrical sample was measured in accordance with ASTM C496. Using a compressometer and a Universal Testing Machine (UTM), cylindrical concrete samples will be tested for the determination of strength properties.

Alkali-silica reactivity (ASR) will be performed to measure the expansion of FFC mixtures in the presence 
of alkaline water and reactive aggregates (sands in this case). The ASR test procedure will be performed as per ASTM C1567-13 and ASTM C1260-14 methods. A cement-sand ratio of 1:2:25 and a water-cement ratio of 0.47 will be maintained while preparing the mortar bars. Three specimens will be prepared for each test condition, and they will be kept in a moist condition for 24 hours. Afterward, the mortar bars will need to be placed in $1 \mathrm{~N}$ $\mathrm{NaOH}$ solution for the next 14 days and intermediate expansion readings at 4,8,12, and 14 days will be counted. A linear variable differential transducer (LVDT) will be used to measure the expansion readings. The ball drop test on FFC mix determines the ability of flowable fill mix to withstand the repeated loading by dropping a metal weight onto the in-place material. The ASTM D6024 method has been followed to perform this experiment.

\section{Results and decisions}

\subsection{Specific surface area}

Specific surface areas of all RHAs and cement were measured through the BET surface area method. It was observed that the specific surface area increased with the decreasing size of particles, which was expected. The specific surface areas of RHA-1 and RHA-2 were found to be $18.038 \mathrm{~m}^{2} / \mathrm{g}$, and $22.114 \mathrm{~m}^{2} / \mathrm{g}$, respectively. The specific surface areas of the Type I OPC was found to be $47.178 \mathrm{~m}^{2} / \mathrm{g}$. The outcome of the specific surface area of different sizes of RHAs used in this study followed the same trend as the findings of another research conducted by Habeeb and Mahmud [11].

\subsection{Flowability test}

A high flowability is needed for flowable fill mix. At the same time, the mixture will need to be proportioned to produce a mixture without segregation. As per ASTM D6103, the typical flow of the flowable fill mixture will have to be 20 to $30 \mathrm{~cm}$ ( 8 to 12 in.). Bleeding is another important issue related to flowable fill mix which causes particle settlement and the upward migration of water and accumulation of water at the surface of the mixture. Excessive bleeding can result in the reduction of strength and durability while contributing to post-placement subsidence. Flowability and bleeding both depend primarily on the water content of the mixture. Figure 2 shows the flow measurement of control flowable fill mix with a w/c ratio 1.7 . The measured flow was found to be $12.5 \mathrm{~cm}$ which is very low compared to the standard flow value. Flowable fill having flowability below $20 \mathrm{~cm}$ will hinder the self-compacting ability of the mixture.

On the other hand, Figure 3 shows the control mix with w/c ratio 1.9 that resulted in a $28 \mathrm{~cm}$ flow diameter, which is under the satisfactory level as per ASTM 6103. It shows that with the increase of water content in the mixture, the flowability of the mixture increased. However, excess addition of water will cause bleeding and segregation problem of the flowable fill mix. An optimum $\mathrm{w} / \mathrm{c}$ ratio is expected to maintain for the ideal mix design.

\subsection{Field demonstration}

With the help of Arkansas Ready Mix Concrete Association (ARMCA), the research team has organized a lunch and learn workshop on the application of RHA in flowable fill on November 27, 2018, in Jonesboro, Arkansas. The team delivered an oral presentation based on the laboratory test results of RHA-modified regular concrete and FFC mixtures, which was followed by field mixing and placement operation in a small trench (48inch $\times$ 9-inch $\times$ 8-inch) with a 2 in. diameter pipe. An FFC mix with $40 \%$ RHA-1 and $60 \%$ cement was prepared. Figure 4 shows the location of a borrow pit, where the FFC mixture was placed. The research team also plans to monitor these sites after the placement of FFC mixture. Several ArDOT and City Engineers, local ready-mix concrete company engineers, and plant operators from northeast Arkansas attended this lunch and learn session (Figure 5). Besides the technology transfer of gained knowledge, this session also helped the research team to engage the audience in open discussion on current research on assessing the feasibility of RHA as a construction material in Arkansas.

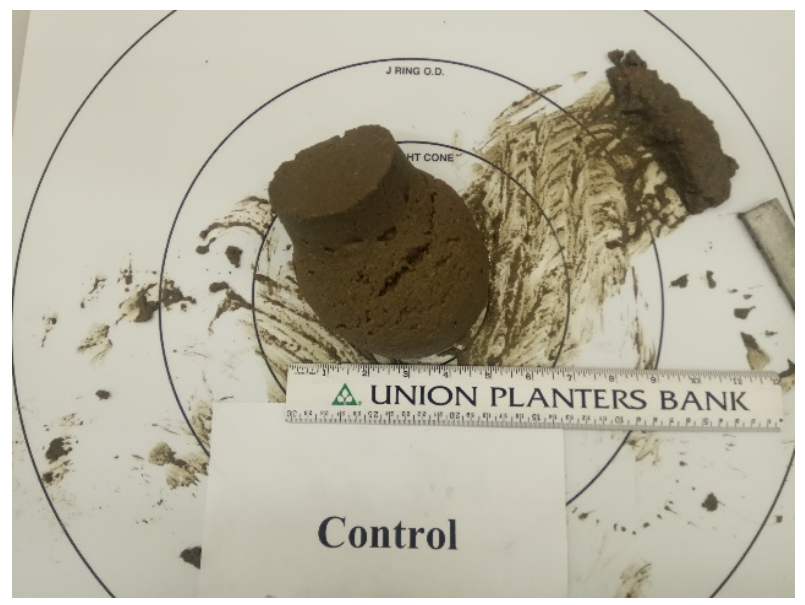

Fig. 2. Flowability of control mix with $1.7 \mathrm{w} / \mathrm{c}$ ratio.

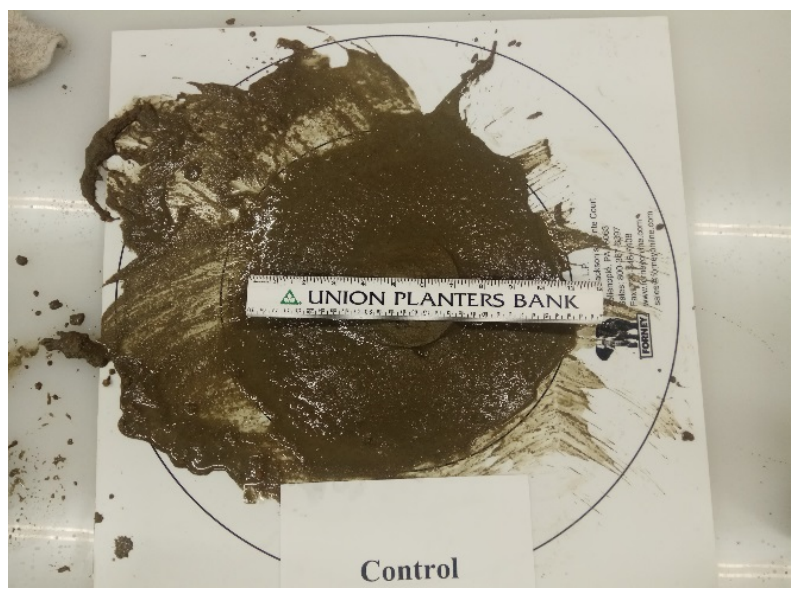


Fig. 3. Flowability of control mix with 1.9 w/c ratio.
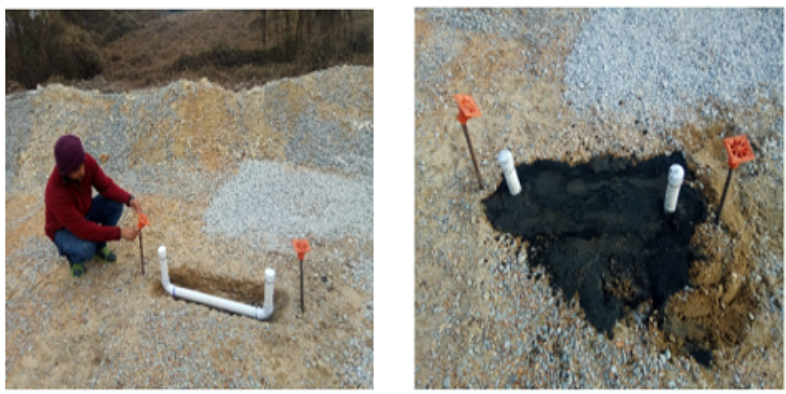

Fig. 4. RHA-modified FFC placement site.

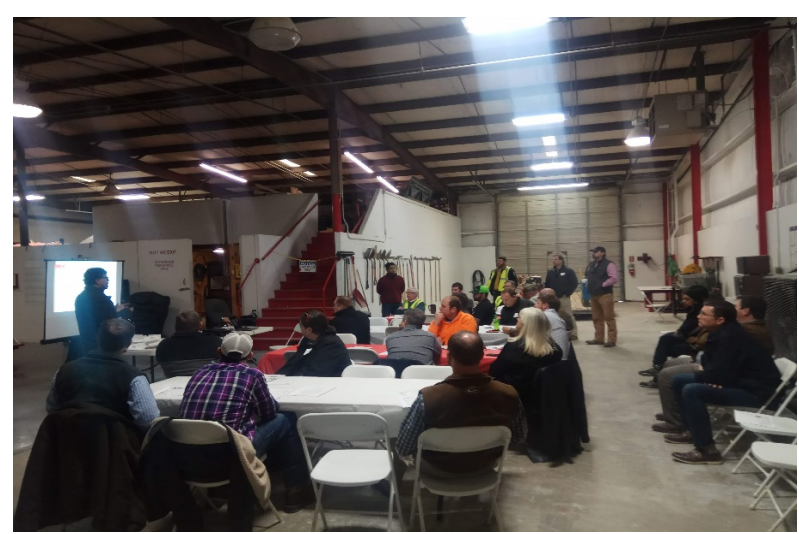

Fig. 5. Lunch and learn session.

\section{Conclusions}

This paper represents a laboratory experimental investigation on RHA-modified flowable fill concrete (FFC) mixtures. The laboratory experimental plan of this study includes physical and chemical properties of raw materials, workability of fresh FFC mixture, and strength properties of hardened FFC samples. The literature review of this project provided in-depth information on flowable fill technology, type, specifications, mix designs, tests methods, current studies, and different application of FFC. Trial mixes for the control FFC were prepared. Laboratory test results showed that with w/c ratio 1.9 , the flowable fill mix resulted in satisfactory flowability. A field demonstration of an FFC mix was successful. Based on the limited findings of this ongoing study, it can be said that the high percentage of silica content in RHA makes it a potentially sustainable source of raw material for the concrete industry. Due to its low specific gravity, RHA can be used to produce lightweight flowable fill concrete. The outcome of this study is expected to help transportation agencies and construction industries for finding a cost-effective and environment-friendly construction material.

The authors would like to acknowledge the financial support from the Transportation Consortium of South-Central States (Tran-SET). The authors are also grateful to ARMCA members, City of Jonesboro, NEAR Ready Mix Concrete, Razorback Concrete, and Riceland Foods for helping the research team in different aspects of this project that include facilitating the workshop, lending placement sites, plant- mixing of RHA-modified FFC, providing the test materials, and providing technical support.

\section{References}

1. Total U.S. rice production, US Department of Agriculture, National Agriculture Statistics Service, https://www.statista.com/statistics/190470/total-usrice-production-from-2000/, Accessed July 2, 2018.

2. Malhotra V.M., Mehta, P.K. (1996). Pozzolanic and cementitious materials. Gordon and Breacch Publ, Canada, [191p].

3. Cordeiro, G.C., Toledo Filho, R.D. and de Moraes Rego Fairbairn, E. (2009). Mater Struct 42: 983. https://doi.org/10.1617/s11527-008-9437-z, Springer Netherlands.

4. Sensale de, G.R. (2006). Strength development of concrete with rice-husk ash. Cement and concrete composites, 28(2), 158-160.

5. Ahsan, M. and Hossain, Z. (2018). Potential of Rice Husk Ash (RHA) as a Supplementary Cementitious Material in Concrete, Advances in Civil Engineering Materials, https://doi.org/10.1520/ACEM20170114. ISSN 2379-1357.

6. National Ready Mix Concrete Association. (1989). What, Why \& How? Flowable Fill Materials. Concrete in Practice, CIP, 17, 900.

7. Memon, S.A., Shaikh, M.A., and Akbar, H. (2011). Utilization of rice husk ash as viscosity modifying agent in self-compacting concrete. Construction \& Building Materials, 25(2), 1044-1048.

8. Pierce, C.E. and Blackwell, M.C. (2003). Potential of scrap tire rubber as lightweight aggregate in flowable fill, Waste Management, 23(3), 197-208, ISSN 0956-053X,https://doi.org/10.1016/S0956053X(02)00160-5.

9. Venkatanarayanan, H.K. and Rangaraju, P.R. (2013). Material Characterization Studies on Lowand High-Carbon Rice Husk Ash and Their Performance in Portland Cement Mixtures. Advances in Civil Engineering Materials, 2(1), 266287, doi:10.1520/ ACEM20120056. ISSN 21653984.

10. Givi, A.N., Rashid, S.A., Aziz, F.N.A., and Salleh, M.A.M. (2010). Contribution of rice husk ash to the properties of mortar and concrete: a review. J. of American Science, 6(3), 157-165.

11. Habeeb, G.A., and Mahmud, H.B. (2010) Study on properties of rice husk ash and its use as cement replacement material. Materials Research, 13(2), 185-190.

12. El-Dakroury, A., and Gasser, M.S. (2008) Rice husk ash (RHA) as cement admixture for immobilization of liquid radioactive waste at different temperatures. Journal of Nuclear Materials, 381(3), 271-277. 